\title{
XXVIII. On the theory of sound, in reply to Professor Challis
}

\section{G.G. Stokes M.A.}

To cite this article: G.G. Stokes M.A. (1849) XXVIII. On the theory of sound, in reply to Professor Challis, Philosophical Magazine Series 3, 34:228, 203-204, DOI: $10.1080 / 14786444908646210$

To link to this article: http://dx.doi.org/10.1080/14786444908646210

曲 Published online: 30 Apr 2009.

Submit your article to this journal ๘

Џ Article views: 7

Q View related articles ¿ 
plied to the purpose of rendering a meridian mark visible at night; and that the same means might also be used for illuminating the wires of the transit instrument. I proposed that the meridian mark should consist of a hole in a plate of brass, adjustible in a vertical and horizontal direction by screws, and that behind this hole should be placed the incandescent wire in a glass tube for the purpose of illumination, the battery being of course at any required distance. For illuminating the wires of the telescope, I proposed that the platinum wire, protected by a glass tube, should be placed either within or at the side of the eye-piece, and thus obviate the necessity of piercing one of the transit-arms, as is usual. I was only able to try the above plans upon a small scale for want of a more powerful battery; but the experiments of Mr. Staite lead me to think that there may be cases in which his method of illumination by galvanism might be used with the greatest advantage for rendering a very distant meridian mark visible. I have found that even platinum wire, rendered incandescent by alcohol, may be distinguished by the telescope at a considerable distance; as may also the hydrogen and platinum lamp. By any of the above plans, the necessity of attention to the lamp itself by an assistant is done away.

While upon the subject of micrometer-wires, may $I$ also be allowed to state, that so far back as $1831 \mathrm{I}$ invented a substitute for them by lines drawn upon glass with a diamond, which lines were illuminated through the edge of the glass? but $I$ was led to abandon the plan after trial, fearing to introduce the errors of tice two surfaces of the glass, though I found that in other respects the plan fully answered. I am induced to mention this, having lately seen in the public prints that the same method has been since independently discovered, and I rejoice to find satisfactorily employed, by the Earl Rosse.

XXVIII. On the Theory of Sound, in reply to Professor Challis. By G. G. Stokes, M.A., Fellow of Pembroke College, Cambridge*.
$\mathrm{S}$ the subject of plane waves does not seem likely to be
elucidated by further discussion, I pass on to spherical waves.
Professor Challis has divided his demonstration of the "contradiction" arrived at in this case into five heads. I entirely agree with the first four; the fifth I beg leave to dis- pute. The part to which I object is contained in the sentence,
* Communicated by the Author. . 
"Hence by the principle of the constancy of mass employed in investigating one of the hydrodynamical equations, thiose two quantities must be equal to each other." I deny that the equality follows in any manner from the principle in question. As the onus probandi evidently rests with Professor Challis, I might here stop; but to render everything as definite as possible, I will give a precise enunciation of the principle of the constancy of mass, at least as I myself regard it, and I have no reason to suppose that Professor Challis differs from me in this respect.

Let $S$ be any closed surface, finite or infinitesimal, drawn in the fluid at the time $t, \tau$ any finite or infinitesimal interval of time; and at the time $t+\tau$ let the surface $S^{t}$ be the locus of the particles which at the time $t$ were situated in the surface $S$ : then the mass contained within the surface $S^{\prime}$ at the time $t+\tau$ is equal to the mass contained within the surface $S$ at the time $t$.

The principle of the constancy of mass might lave been enunciated somewhat differently, as follows; and it will be easily seen that the two enunciations come to the same thing.

Let $\mathbf{S}$ be any closed surface, finite or infinitesimal, drawn within the fluid and renaining fixed in space; and let $M$ be the whole mass of fluid which flows across the surface $S$ during the time $\tau$, those portions being reckoned positive which flow from without to within $S$, and those negative which flow from within to without: then the mass contained within the surface $S$ at the time $t+\tau$ exceeds the mass contained within the same surface at the time $t$ by the quantity $M$.

I will not at present say anything about the paragraph which follows (5.); because if Professor Challis and 1 can agree about (5.), we shall probably have little difficulty in agreeing about the paragraph in question.

Neither will I pursue the discussion further in the present communication; because, in addition to the motives which I have already mentioned for declining to do so, it seems to me that too great discursiveness is an evil in controversy, especially in mathematics, where one false step may invalidate all that follows. I think it best to discuss only one fundamental point at a time.

Pembroke College,

Feb. 3, 1849. 